\title{
Estruturas paratáticas de que-conetivo em frases não-argumentais
}

\author{
Gabriela Matos* \& Patrícia Rodrigues** \\ *Universidade de Lisboa, **Universidade Federal do Paraná
}

\begin{abstract}
:
In European and Brazilian Portuguese gramatical tradition, non-argumental clauses introduced by que 'that' have been classified as causal explicative clauses. However, differently from the other explicative conetives, que may head non-argumental clauses displaying other meanings, such as result/consequence or simultaneous temporal readings. We take these different readings as resulting from the context, and we assume that the main semantic import of que is acting as a sentence connector marker. Yet, despite the differences in the interpretation of queclauses, from a syntactic point of view, these clauses behave alike. We argue that they are parenthetical sentences, extending previous work on European Portuguese.
\end{abstract}

Keywords: Connective-que, explicative and non-explicative values, hypotaxis, parataxis, parenthetical clauses

Palavras-chave: Que-conetivo, valores explicativos e não explicativos, hipotaxe, parataxe, orações parentéticas

\section{Introdução}

As orações iniciadas pela forma conjuncional que têm sido classificadas, de acordo com o seu grau de integração gramatical, como casos de hipotaxe (1), de parataxe (2) e de insubordinação (3):

(1) Ele disse que arrumava o dicionário.

(2) Compre os ovos, que eu quero fazer um bolo.

(3) Que viene (Espanhol) (Gras; Sansiñena, 2015: 507)

'(Ele/Ela) vem.'

A principal função desta forma conjuncional é relacionar a frase que encabeça com conteúdo oracional/contextual prévio. Nesse sentido, todas as instâncias de que nos exemplos dados podem ser consideradas casos de que-conetivo. Porém, os contextos em que ocorrem diferem: em (1), que introduz uma frase subordinada com estatuto argumental selecionada pelo verbo da frase matriz; em (2), que inicia uma frase não-argumental, parcialmente autónoma relativamente à frase com que está conectada, com a qual a frase de que estabelece uma relação de parataxe; em (3), que conecta o enunciado expresso com um discurso prévio não linguisticamente explicitado, relativamente ao qual é gramaticalmente independente.

O presente artigo tem como objetivos principais analisar orações de que-conetivo não-argumentais, ilustradas em (2), comumente descritas como causais explicativas ${ }^{1}$, e determinar a natureza da relação paratáctica que as frases conectadas estabelecem entre si. Além de mostrarmos que que-conetivo não-argumental constitui um caso à parte relativamente aos outros conectores que iniciam orações explicativas tradicionalmente assumidas como casos de

${ }^{1}$ No presente texto não nos debruçaremos sobre propostas que procuram estabelecer uma relação entre que-conetivo e insubordinação, deixando essa análise para trabalho futuro. 
parataxe/coordenação, como pois, e porque (e.g. Said Ali, 1931; Cunha; Cintra, 1984; Lobo, 2003), evidenciaremos que nem todas as instâncias das orações de que-conjuntivo não-argumental devem ser analisadas como causais explicativas.

Com efeito, devido ao seu valor meramente conetivo, as frases iniciadas por que-conetivo não-argumental podem ocorrer em construções denotando diversos valores, um facto assinalado para outras línguas, entre as quais o alemão (Reis, 1997; Heycock, 2006) e o espanhol (Demonte; Fernández-Soriano, 2014, Etxeparre, 2014), mas que tem permanecido não explorado para o português. $\mathrm{O}$ exemplo em (4a) ilustra uma frase iniciada por queconetivo que não possui valor causal explicativo. Assim, quando comparamos o exemplo (4a) com o exemplo (2), percebemos que em (2) o conector que pode ser substituído por porque (4b), mas que este não é o caso de (4a), como ilustrado em (4c), que é um enunciado pragmaticamente pouco natural.

(4) a. Compre os ovos, que eu faço o bolo de banana.

b. Compre os ovos, porque eu quero fazer um bolo de banana.

c. \#Compre os ovos, porque eu faço o bolo de banana.

No entanto, apesar das diferenças de interpretação que podem instanciar, as frases não-argumentais de queconetivo apresentam um comportamento sintático semelhante, partilhando propriedades com a subordinação e a coordenação, como já evidenciado para as explicativas causais em Matos (2004, 2006) e Colaço; Matos, (2016a,b). Assim, à primeira vista, a natureza híbrida entre a parataxe e a hipotaxe das construções de que-conetivo nãoargumental levanta a questão de saber se faz sentido reduzir este conector a uma conjunção coordenativa, ou a um complementador (marcador de subordinação), ou ainda a uma nova categoria, criada com o propósito exclusivo de dar conta deste tipo de construções, por hipótese Conj_Comp.

Esta questão coloca-se com acuidade ao nível da estrutura sintática, assumindo, de acordo com a hipótese da estrutura sintagmática nua (bare phase structure), que os sintagmas não são intrinsecamente distintos dos núcleos que os encabeçam (Chomsky, 1995), e apresentam a natureza categorial (ou etiqueta, ing. label) do núcleo que se projeta (Chomsky, 2013, 2015).

Admitimos que esta questão pode ser resolvida sem se assumir a existência de uma nova categoria funcional híbrida, adotando a proposta de Colaço \& Matos $(2016 \mathrm{a}, \mathrm{b})$ para as orações explicativas. Em conformidade, consideraremos que estas construções envolvem mais de uma camada de estrutura sintática, cada uma delas projetada a partir de um núcleo funcional próprio: que-conetivo é o conector que encabeça localmente o núcleo $\mathrm{C}(\mathrm{omp}) \mathrm{da}$ frase que introduz; adicionalmente esta frase, que apresenta um estatuto parentético, marcado prototipicamente por pausas, frequentemente vírgulas, é conectada com aquela com que está relacionada por um núcleo sem realização lexical, Par(entese), que estabelece a relação paratática entre as frases conectadas.

O artigo está organizado da seguinte forma: na secção 2, discutimos as distinções entre as orações de queconetivo e as orações causais com porque e pois e mostramos que o que se distingue de porque e pois por não apresentar um valor causal intrínseco. Em seguida, na seção 3, mostramos que as orações de que-conetivo modificadoras de um ato de fala assumem sentidos diversos conforme o contexto em que aparecem. Na secção 4 , expomos nossa proposta de análise para estas orações, e, na secção 5, apresentamos as nossas considerações finais. 
Estruturas paratáticas de que-conetivo em frases não-argumentais

\section{Que-conetivo e orações causais explicativas}

Na tradição gramatical luso-brasileira, as frases de que-conetivo não-argumental têm sido incluídas nas orações causais explicativas a par das orações encabeçadas por pois e de algumas ocorrências de porque ${ }^{2}$. No seu conjunto, estas frases foram analisadas ora como coordenadas, ora como subordinadas, ou ainda como coordenadas ou subordinadas, dependendo dos contextos (e.g. Said Ali, 1931; Cunha e Cintra, 1984). Segundo esta tradição, as orações causais explicativas distinguem-se das causais próprias: tipicamente, as causais próprias denotam a causa real da situação reportada na oração com que estão conectadas (5). Já as causais explicativas explicitam, fundamentalmente, a razão por que o falante acredita que essa oração seja verdadeira (6) ou o motivo pelo qual a oração correlata foi proferida/enunciada (7). ${ }^{3}$ Nos termos de Sweetser (1990), teríamos orações pertencentes ao domínio do conteúdo (5), ao domínio epistémico (6) e ao domínio do ato de fala (7).

(5) a. Telefonei porque /*pois/*que tenho saudades vossas.

b. Telefonei, porque/pois/que tenho saudades vossas.

(6) a. Choveu, porque / pois / que a estrada está molhada.

b. Aconteceu um acidente, porque / pois / que o airbag abriu.

c. A Maria deve estar doente, porque / pois / que ainda não apareceu nas aulas.

(7) a. Esse biscoito, Aymoré chocolate, é o de Flávia, que o meu é com côco. ( $\sqrt{ }$ porque / $\sqrt{ }$ pois)

(Linguateca, C-Oral-Brasil v. 3.2)

b. Compre os ovos, que / pois / porque eu quero fazer um bolo.

c. Vou-me embora, que / pois / porque me estão esperando.

É necessário observar, contudo, que não há, como considerou usualmente a tradição gramatical, uma relação direta entre a natureza semântica das orações causais próprias ou explicativas e a sua estrutura sintática, prosódica e informacional, o que já foi observado noutros estudos (veja-se, por exemplo, Matos 2004, 2006; Lobo 2013; Rodrigues 2018). Assim, argumentamos que as orações causais próprias (ou causais de conteúdo), que denotam a causa da situação expressa na oração principal, podem realizar-se como orações adverbiais tanto integradas (5a), como não-integradas (5b), dependendo da estrutura informacional da frase (cf. Rodrigues, 2018). A marginalidade de (5a), indica que os conectores pois e que, em frases não-argumentais, só podem ocorrer em frases não-integradas.

Desta forma, em ambos os exemplos de (5), a interpretação da causal pode ser captada pela paráfrase em (8). No entanto, a frase em (5a) forma uma unidade prosódica (representada pela ausência de uma vírgula separando as orações), e a oração causal, por responder à pergunta "Por que telefonaste?", corresponderia ao foco da frase, constituindo, portanto, uma oração integrada (cf. também Lobo, 2003; Haegeman, 2012; entre outros). Pelo contrário, essa pergunta não pode ser respondida, por "pois/que tenho saudades vossas"; por outras palavras, a oração introduzida por "pois" ou "que" não pode constituir o foco da frase. Numa frase como (5b), em que não há uma unidade prosódica, mas dois atos de fala distintos (marcados pela presença da vírgula), a oração causal pode expressar a razão da ação denotada na oração principal, mas, sintaticamente, é uma oração não-integrada,

\footnotetext{
${ }^{2}$ Não apresentaremos frases com porquanto, um conector integrado nas conjunções explicativas por Cunha e Cintra (1984), que tem um sentido próximo de posto que ou na medida em que, uma vez que é pouco usado. Nesta circunstância, é possível que a não total aceitabilidade de (i) se deva ao facto de porquanto estar a cair em desuso:

(i) ?Compre os ovos, porquanto eu quero fazer um bolo.

${ }^{3}$ A ocorrência de que em frases como (5b) e (6a-b) não é consensual. Vários falantes, entre os quais um dos revisores da versão prévia deste trabalho, aceitam-na, enquanto outros falantes a sentem como problemática. Discutiremos esta questão mais adiante no texto.
} 
introduzida pelo falante para explicitar a razão do telefonema, mesmo que essa razão não tenha sido expressamente solicitada. Neste caso, tanto porque, como pois e que são aceitáveis. Um contexto possível para a produção da frase (5b) seria como resposta à pergunta: Telefonaste? (e não Por que telefonaste, como em (5a)).

(8) A razão por que eu telefonei foi ter saudades vossas.

Assumimos que as causais próprias podem, então, ser integradas ou não-integradas. Quando integradas, modificam diretamente a situação denotada pela oração principal e constituem o foco da frase; quando nãointegradas, apresentam uma razão para o conteúdo da oração principal, sem lhe modificar o predicado diretamente, constituindo um ato de fala independente. A previsão é, assim, que causais integradas e não-integradas podem coocorrer na mesma frase, como em (9), que poderia ocorrer como resposta à pergunta Por que é que a Maria se foi embora?.

(9) A Maria foi-se embora porque estava cansada, porque/pois/que ela trabalhou muito hoje.

Esta não é a análise encontrada na grande maioria dos trabalhos sobre as causais/explicativas. De modo geral, associa-se a interpretação de relação causal própria a um enunciado que forma uma unidade prosódica, uma só asserção, logo com a análise da oração causal necessariamente como foco da construção e como oração integrada, como em Lopes (2012), por exemplo:

[...] há construções causais que operam no plano semântico (as chamadas causais de conteúdo, causais de re ou causais de enunciado), explicitando um nexo de causa/consequência entre situações do mundo descritas ao nível dos conteúdos proposicionais articulados através do conector, e dando origem a um enunciado que funciona como uma unidade entoacional e corresponde a uma só asserção [...]. Lopes (2012: 453)

Já as causais ditas explicativas, que, conforme Lopes (2012), operam no plano pragmático, só podem ser analisadas como orações não-integradas por constituírem atos de fala independentes e não se referirem diretamente à situação denotada pela oração principal. Este é o caso das orações em (6) e em (7). Em (6), a oração causal constitui uma evidência para a conclusão enunciada na oração matriz: em (6a), o falante observa a estrada molhada e infere que choveu; em (6b), o falante parte do facto de que o airbag abriu para concluir que aconteceu um acidente; em (6c), igualmente, há uma relação epistémica, resultado de um processo inferencial: a partir do conhecimento do facto de que a Maria não apareceu nas aulas, bem como do conhecimento sobre a plausibilidade a Maria estar doente ser a causa de ter faltado às aulas, o falante enuncia a conclusão de que a Maria está doente. Assim, poderíamos parafrasear os exemplos em (6) como em (10). Neste caso, como afirma Lopes (2012), "estamos perante uma sequência de atos discursivos ou ilocutórios: uma asserção inicial que configura o ato principal, e uma segunda asserção, que funciona retroativamente como justificação da primeira, realizando um ato subordinado" (p. 455).

(10) a. Choveu. Acho que choveu pelo facto de a estrada estar molhada.

b. Aconteceu um acidente. Penso que aconteceu um acidente pelo facto de o airbag abrir.

c. A Maria não apareceu nas aulas. Acredito que a Maria deve estar doente pelo facto de não ter aparecido nas aulas. 
Estruturas paratáticas de que-conetivo em frases não-argumentais

É, contudo, de salientar que pode haver ambiguidade, em alguns casos, relativamente à interpretação da oração principal como uma afirmação a partir de um facto ou como uma conclusão, como é o caso da frase em (11). No primeiro caso, o falante constata que a estrada está molhada e acrescenta, sob a forma de comentário, a razão para tal; no segundo caso, o falante sabe que choveu e conclui que a estrada está molhada. Em ambos os casos, tem-se duas asserções independentes, e a oração causal é não-integrada.

(11) A estrada está molhada, porque/pois/que choveu.

Já em (7), as frases iniciadas pelos conectores podem ser parafraseadas por uma expressão que justifique o ato de fala expresso pela oração com que está conectada, como em (12). Como as orações em (6), as orações em (7) também não são integradas, e realizam atos de fala distintos. ${ }^{4}$

(12) a. Esse biscoito, Aymoré chocolate, é o de Flávia, afirmo isto porque o meu é com coco.

b. Compre os ovos, peço isto porque eu quero fazer um bolo

c. Vou-me embora, digo isto porque me estão esperando.

Em suma, os dados acima mostram que os conectores porque, pois e que não possuem o mesmo estatuto sintático: porque pode introduzir tanto orações integradas como não-integradas, ao passo que pois e que só podem introduzir orações não-integradas. Como a literatura relaciona frequentemente o estatuto sintático da oração causal à sua interpretação, é muito comum a denominação de pois e que como conectores explicativos; no entanto, essa denominação não é a mais adequada se a compreensão é de que conectores "explicativos" introduzem sempre orações explicativas, pois muitas frases, como (5b) com os conectores pois e que, teriam a sua análise bastante dificultada: o conector é explicativo, mas introduz uma oração que expressa a razão pela qual ocorreu a ação denotada pela oração principal.

É necessário observar que, muitas vezes, os falantes têm relutância em aceitar dados com o conector que introduzindo causais de conteúdo e causais epistémicas, como em (5b) e (6a-b), respectivamente (ver nota 3 ). Observe-se também o contraste entre as frases abaixo, em (13) e (14) ${ }^{5}$.

(13) a. *Telefonei, que tenho saudades deles.

b. Vou telefonar, que tenho saudades deles.

(14) a. ??Choveu, que a estrada está molhada.

b. Deve ter chovido, que a estrada está molhada.

As frases em (13) expressam uma relação causal de conteúdo e as frases em (14), uma relação causal epistémica. Um dos revisores sugere que os valores de modalidade da oração principal condicionam tanto as leituras possíveis como a aceitabilidade das orações introduzidas por que. Argumentamos que uma restrição deste tipo está presente no caso das frases em (14), mas não necessariamente no caso das frases em (13). No caso de uma relação

${ }^{4}$ É possível argumentar, como apontou um dos revisores deste artigo, que a frase em (7a) pode ser analisada como uma relação causal no domínio epistémico, caso em que o falante conclui que o biscoito é (deve ser) o de Flávia, porque ele sabe que o dele é com coco. Da mesma forma, é possível que a frase em (7c) seja interpretada como uma relação causal no domínio do conteúdo, em que o falante apresenta uma razão para o facto de se estar indo embora.

${ }^{5}$ Os exemplos em (13), bem como os contrastes de aceitabilidade em (13) e (14), foram sugeridos por um dos revisores do artigo. 
epistémica, a oração causal justifica uma inferência, uma conclusão, enunciada na oração principal. Assim, na presença de um verbo epistémico como dever em (14b), a única interpretação disponível para a oração principal é a de uma inferência/conclusão, uma possibilidade; logo, a interpretação da oração causal é facilmente alcançada como uma justificação para a enunciação dessa conclusão. Na ausência de um modal desse tipo, como em (14a), é mais difícil determinar se a oração principal, por si só, enuncia uma conclusão ou um facto; a pista para interpretála como uma inferência vem justamente da oração causal: dado nosso conhecimento de mundo, não é possível interpretar a estrada molhada como causa da chuva, logo ela será interpretada como uma justificação para a enunciação da oração principal.

No caso de (13), contudo, acreditamos que as leituras obtidas não são condicionadas pelo uso do pretérito perfeito na oração principal ou de outros tempos na oração causal. Por exemplo, como referimos acima a propósito de (5b), a frase em (13a) tem melhor aceitação, num contexto de diálogo, como resposta a uma pergunta como Afinal, sempre telefonaste? Outros exemplos, como os de (15), com os mesmos tempos verbais, tem maior aceitabilidade.

(15) a. A Maria comprou um carro, que agora ela tem dinheiro.

b. Telefonei ontem para o médico, que o meu filho está muito engripado.

Não rejeitamos, contudo, completamente, a hipótese de que as orações introduzidas por que possam ter uma aceitabilidade mais restrita nas relações causais em domínios do conteúdo e epistémico, diferentemente dos conectores porque e pois. É possível observar um contraste desse tipo em (16). No entanto, (17), que difere de (16c) apenas pela inclusão nas frases conectadas de elementos intensificadores, é perfeitamente aceitável.

(16) a. A estrada está molhada, porque choveu.

b. A estrada está molhada, pois choveu.

c. ??/*A estrada está molhada, que choveu.

(17) A estrada está completamente alagada, que choveu a noite inteira!

Argumentamos que o que aparentemente está em causa nos contrastes observados é a falta de conteúdo causal intrínseco de que-conetivo, por oposição a porque e a pois. Nesse sentido, as orações introduzidas por que necessitam de um contexto mais detalhado para sua interpretação quando o nexo causal/explicativo é exigido.

Admitimos, pois, que o nexo causal assumido por que é fundamentalmente construído a partir do conteúdo das frases conectadas. Uma relação causal própria com modificação direta do predicado exige o conector porque, com conteúdo causal intrínseco, diferentemente de uma relação causal no domínio epistémico ou no domínio de ato de fala. Nesse tipo de contexto, em que o predicado é o alvo da modificação, pois e que não são possíveis. Uma relação causal no domínio epistémico aparenta uma preferência por conectores com valores causais intrínsecos, mas um contexto mais detalhado pode facilitar a presença de um conector neutro como que. Nestes casos, observa-se que que é sempre equivalente a porque, ou seja, assume sempre um valor causal/explicativo. Esta é uma diferença crucial no tocante às orações introduzidas por que-conetivo relativas a um ato de fala: nestes casos, como discutiremos na próxima seção, que pode assumir outros valores além do valor de causa/explicação, como o valor de consequência/resultado.

Em suma, propomo-nos examinar neste trabalho orações de que-conetivo que modificam um ato de fala, como nos exemplos em (4a) e em (7), ou que se relacionam com uma proposição no domínio epistémico, como (6). Como 
Estruturas paratáticas de que-conetivo em frases não-argumentais

as relações no domínio do ato de fala não exigem conectores com sentidos específicos, as orações de que-conetivo nesse domínio são amplamente aceitáveis e têm maior liberdade interpretativa. Frey (2016), por exemplo, sugere que uma menor integração sintática permite uma maior liberdade interpretativa da oração. Por outro lado, as relações no domínio epistémico e de conteúdo expressam caracteristicamente uma relação causal/explicativa. Acreditamos que, embora a neutralidade de que não favoreça a aceitabilidade das orações de que-conetivo nesses contextos, o estatuto parentético destas orações permite que ocorram como um modificador não-integrado da proposição associada.

\section{Nexos não-explicativos em orações de que-conetivo}

A ausência de conteúdo semântico intrínseco de que-conetivo não-argumental manifesta-se na possibilidade de este elemento surgir em conexões frásicas sem nexo explicativo, em que os termos oracionais articulados estabelecem uma relação de antecedente-consequência ou ainda de simultaneidade temporal.

\subsection{Nexo de consequência/resultado}

Em exemplos como (17), a frase introduzida por que não exibe preferencialmente um valor causal explicativo, como mostra a pouca naturalidade de comutação de que com porque em (18), ou a dificuldade de parafrasear a oração iniciada por que em (17) por uma expressão que apresente uma justificação da enunciação da oração relacionada (19):

(17) Compre os ovos, que eu faço o bolo

(18) \#Compre os ovos, porque eu faço o bolo.

(19) *Compre os ovos. Digo/Peço isto porque eu faço o bolo.

Na verdade, a oração-que em (17) explicita preferencialmente uma situação que ocorre como consequência da situação expressa na oração precedente. Daí a possibilidade de parafrasear a frase complexa em (17) por uma frase contendo como oração inicial uma subordinada condicional (20), ou por uma estrutura de coordenação frásica em que o segundo termo explicita uma situação que decorre da situação expressa pelo primeiro termo coordenado (21):

(20) Se (você) comprar os ovos, eu faço o bolo.

(21) Compre os ovos e eu faço o bolo.

Note-se que em (17), ainda que marginalmente, a frase iniciada por que pode assumir um valor explicativo. Porém, neste caso, tal como em (20), pressupõe-se uma oração condicional subentendida/elíptica:

(22) a. Compre os ovos, que se comprar os ovos eu faço o bolo. (cf. (17))

b. Compre os ovos, porque se comprar os ovos eu faço o bolo. (cf. (18))

O mesmo valor de consequência ocorre também preferencialmente nas orações de que-conetivo em (23).

(23) a. Passe-me o telefone, que eu ligo já para o restaurante. 
b. Come a sopa toda, que eu dou-te um gelado! ${ }^{6}$

c. Trabalha com afinco, que resolves o problema!

Para todas elas é possível construir paráfrases envolvendo condicionais (24) ou estruturas coordenadas (25), em que o segundo termo frásico é assumido como a consequência ou resultado da situação denotada pelo primeiro termo:

(24) a. Se me passar o telefone, eu ligo já para o restaurante.

b. Se comeres a sopa toda, eu dou-te um gelado!

c. Se trabalhares com afinco, resolves o problema!

(25) a. Passe-me o telefone, e eu ligo já para o restaurante.

b. Come a sopa toda, e eu dou-te um gelado!

c. Trabalha com afinco, e resolves o problema!

Note-se que nos exemplos em (17) e (23) o valor de consequência não se identifica com o das orações consecutivas determinadas por uma expressão graduada ou quantificada do primeiro termo oracional, realizadas ou implícitas, como as ilustradas em (26).

(26) a. Ela comeu tanto/de tal modo que ficou doente.

b. Estou tão cansada que tenho de parar!

c. Ela está de tal modo que nem pode!

De facto, as frases em (17) e (23) não têm paráfrases graduáveis bem formadas:

(27) a. *Compre os ovos, (tanto/de tal modo) que eu faço o bolo.

b. *Passe-me o telefone, de tal forma que eu ligo já para o restaurante.

b. *Come a sopa toda, de tal forma que eu dou-te um gelado!

c. *Trabalha com afinco, de tal modo que resolves o problema!

Há casos mesmo em que a frase iniciada por que pode assumir mais de uma leitura, como em (28a). Tanto o valor explicativo (28b) como o valor de consequência (28c) estão disponíveis para a interpretação de (28a).

(28) a. Compre a manteiga, que eu vou fazer o bolo de banana.

b. Compre a manteiga, porque eu vou fazer o bolo de banana.

c. Se você comprar a manteiga, eu vou fazer o bolo de banana.

${ }^{6}$ A colocação dos pronomes clíticos nestas frases em português europeu é bastante variável: a par de frases que exibem ênclise, como em (23b), existem outras que requerem próclise, como no exemplo em (i). A análise desta variação está fora do escopo do presente artigo.

(i) Estuda, que te dão boa nota! 
Estruturas paratáticas de que-conetivo em frases não-argumentais

\subsection{Nexo de simultaneidade}

No caso de uma frase como (29a), além da leitura de justificação, que permite a substituição de que por porque (29b), é possível que as frases conectadas expressem uma distribuição de tarefas, como mostra a paráfrase em (29c). O nexo de simultaneidade temporal favorece também uma leitura contrastiva de (29a), parafraseada em (29d).

(29) a. Compre você a manteiga, que eu vou comprar os ovos.

b. Compre você a manteiga, porque eu vou comprar os ovos.

c. Enquanto você compra a manteiga, eu vou comprar os ovos.

d. Você compra a manteiga, enquanto (que)/ ao passo que eu vou comprar os ovos.

Em todos estes exemplos a oração de que-conetivo funciona como um modificador de ato de fala, no caso de orações com uma natureza injuntiva. As diferentes leituras obtidas são resultado de diferenças contextuais, incluindo tempo e modo das orações.

Resumindo, as orações iniciadas por que-conetivo modificadoras de um ato de fala assumem valores distintos, dependendo do contexto. Consideramos que essas diferentes leituras são possíveis essencialmente em virtude da neutralidade semântica do conector que, aliada ao estatuto de modificador parentético dessas orações, objeto de discussão das próximas secções.

\section{O estatuto sintático das orações iniciadas por que-conetivo}

Um conjunto de propriedades relativas à sua estrutura externa e interna aproximam as diferentes manifestações das orações de que-conetivo não-argumental analisadas. Como os exemplos em (30) mostram, independentemente do seu valor explicativo (30a), consequencial (30b) ou de simultaneidade temporal (30c), todas as orações de queconetivo, relativamente à frase com que estão conectadas, são não-integradas, quer discursiva e quer sintaticamente.

Do ponto de vista discursivo, apresentam dois atos de fala prosodicamente assumidos como independentes, usualmente separados por pausa (na escrita, tipicamente uma vírgula). Essa independência, pode, inclusivamente, corresponder à ocorrência de dois atos ilocutórios de natureza diferente, como em (30b) e (30c), em que a primeira oração é injuntiva e a segunda declarativa.

(30) a. Vou(-me) embora, que é tarde.

b. Dê-me o dicionário, que eu guardo na estante.

c. Consulte a gramática, que eu consulto o dicionário.

Sintaticamente, a não integração manifesta-se pela ausência de c-comando por parte de elementos presentes na frase associada relativamente a oração de que-conetivo. Os exemplos em (31) e (32) atestam esta situação. Em (31) a negação frásica da oração inicial não tem escopo sobre a oração de que-conetivo, pelo que não pode negar o seu conteúdo proposicional, daí resultando anomalia pragmática, explicitamente marcada pela impossibilidade da continuação destes exemplos como explicitado entre parênteses.

(31) a. *Não (me) vou embora, que é tarde (mas que estou cansada).

b. *Não me dê o dicionário, que eu guardo na estante (mas que eu guardo na mochila). 
A ausência de c-comando está igualmente presente em (32), como indica a impossibilidade de um quantificador na primeira oração ter escopo sobre a oração de que-conetivo (32a) e na ausência de efeitos do Princípio C da Teoria da Ligação (32b):

(32) a. \#/*Só consulte a gramática, que eu consulto o dicionário.

b. Ele $e_{i}$ tem trabalhado muitas horas por dia, que o João ${ }_{i}$ é um médico muito competente.

\subsection{Orações de que-conetivo e adverbiais não-integradas}

$\mathrm{Na}$ literatura, este comportamento tem sido invocado para distinguir orações adverbiais não-integradas na oração associada de orações adverbiais integradas (Haegeman, 1991/2009, 2012; Lobo, 2003). O contraste entre a marginalidade de (31)-(32) e a aceitabilidade de (33), em que figuram orações adverbiais integradas, parece, pois, sugerir que as orações de que-conetivo não-argumental são adverbiais não-integradas subordinadas:

(33) a. Ela não se vai embora porque é tarde, mas porque está cansada.

b. Ela não me deu o dicionário para que eu guardasse na estante, mas para que eu o consultasse.

c. Ela só consulta a gramática quando eu consulto o dicionário.

Esta hipótese é plausível para as orações causais não-integradas de porque (Rodrigues, 2018), que ocorrem em posições da periferia esquerda ou direita da frase subordinante, como mostram os exemplos em (34B) e (35b):

(34) A: Eu fiquei sabendo que o João casou com uma milionária, e que, dois meses depois, ela morreu num acidente de avião. O que aconteceu com ele? Ficou rico?

B: Ele $_{\mathrm{i}}$ não herdou nada, porque o João $\mathrm{i}_{\mathrm{i}}$ casou com separação de bens. (Rodrigues, 2018: 556)

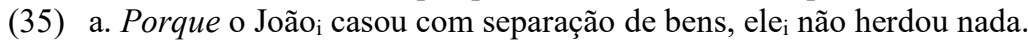

b. Porque ele $_{\mathrm{i}}$ casou com separação de bens, o João ${ }_{i}$ não herdou nada.

Em (34B) a oração de porque na periferia direita da frase é não-integrada, como mostra a ausência de efeitos de Princípio C sobre as expressões nominais correferentes, ele e o João, resultante da ausência de c-comando a partir da frase matriz. Essa mesma ausência de c-comando está presente em (35), em que a oração causal se encontra na periferia esquerda da frase complexa.

Assim, nestes contextos, é possível assumir para as causais de porque a proposta correntemente apresentada para as subordinadas adverbiais não-integradas, ou periféricas: a ausência de c-comando decorre do facto de elas serem inseridas em posições mais altas do que o TP da frase matriz.

Do mesmo modo, poderíamos levantar a hipótese de que as orações de que-conetivo não-argumental devem ser incluídas nas adverbiais não-integradas. No entanto, esta hipótese é problemática, como veremos a seguir.

\subsection{Orações de que-conetivo e coordenação}

Uma propriedade crucial distingue as adverbiais não-integradas das orações de que-conetivo não-argumental. Estas últimas não podem ser antepostas, ocupando a posição inicial da frase associada, como ilustrado em (36), que contrasta em gramaticalidade com (30): 
Estruturas paratáticas de que-conetivo em frases não-argumentais

(36) a. *Que é tarde, vou(-me) embora.

b. *Que eu guardo na estante, dê-me o dicionário.

c. *Que eu consulto o dicionário, consulte a gramática.

O padrão de comportamento ilustrado em (36) foi recorrentemente associado às orações causais explicativas (cf. (37b)) e levaram a que se admitisse que elas estabeleciam com a oração associada uma relação paratática, por vários autores identificada com a coordenação (cf. Cunha \& Cintra, 1984; Lobo, 2003, e.o.). Com efeito, como (38) exemplifica, em estruturas de coordenação, a anteposição de um termo coordenado para o início da estrutura coordenada produz agramaticalidade ${ }^{7}$ :

(37) a. A Maria está em casa, porque/pois/que o carro está na garagem.

b. ??/*Porque/pois/que o carro está na garagem, a Maria está em casa.

(38) a. A Maria está em casa e o carro está na garagem.

b. *E o carro está na garagem, a Maria está em casa.

Contudo, embora assumamos que a relação estabelecida entre a relativa e a oração associada é de natureza paratática, rejeitamos que o tipo parataxe envolvido nas construções de que-conetivo e nas causais explicativas, em geral, seja a coordenação. De facto, a impossibilidade de antepor uma oração não é exclusiva da coordenação (Matos, 2004, 2006), e pode decorrer de diferentes fatores. Assim, por exemplo, esta propriedade surge em estruturas de subordinação que envolvem domínios de ilha, como ilustrado em (39b), (40b) em que a relativa com antecedente e completiva de nome são extraídas do domínio de um DP/SN Complexo:

(39) a. A Maria comprou o carro que está na garagem.

b. *Que está na garagem, a Maria comprou o carro.

(40) a. O João levantou a hipótese de que a Maria estivesse em casa.

b. *De que a Maria estivesse em casa, o João admitiu a hipótese.

Do mesmo modo, alegar que as orações de que-conetivo são coordenadas com base na sua não integração prosódica na frase anterior é um argumento inadequado, na medida em que as estruturas de coordenação podem, também elas, ser integradas ou não-integradas (parentéticas, como proposto em Matos, 2009). Assim, os exemplos em (41) contrastam entre si relativamente ao efeito de escopo do constituinte negativo inicial: em (41a), uma estrutura de coordenação frásica integrada, o advérbio negativo, nunca, na periferia esquerda do primeiro termo coordenado tem escopo sobre um só amigo, que pode ser interpretado como uma expressão negativa sinónima de nenhum amigo. Pelo contrário, em (41b), em que ocorre uma coordenação periférica, nunca não tem escopo sobre a frase coordenada não-integrada e um só amigo é interpretado como uma expressão positiva referindo um amigo

${ }^{7}$ Para caracterizar a coordenação em português foram avançadas outras propriedades, como a impossibilidade de co-ocorrência de conjunções coordenativas ou o padrão de ênclise. No entanto, nenhuma delas é conclusiva. De facto, a coocorrência de conjunções é admissível sempre que elas não disputem a mesma posição estrutural, (i). Quanto à ênclise, assumi-la como uma marca da coordenação em português, seria excluir como mal formadas todas as frases do português brasileiro, que usa preferencialmente a próclise, ou as estruturas do português europeu em que a próclise está presente, por exemplo, quando a conjunção coordenativa é nem, (ii):

(i) O céu está carregado e ou vai chover ou vai nevar.

(ii) Tu não atendeste o telefone nem o Pedro te viu durante todo o dia. 
específico ${ }^{8}$ Contudo, na oração não-integrada, a possibilidade de anteposição da oração iniciada pela conjunção coordenativa continua vedada, como mostra a inaceitabilidade de (42):

(41) a. Nunca o irmão o procurou ou um só amigo lhe telefonou.

b. Nunca o irmão $o$ procurou, e um só amigo lhe telefonou.

(42) *E um só amigo lhe telefonou, nunca o irmão o procurou.

Deste modo, atribuir uma natureza coordenativa às orações de que-conetivo (ou às causais "explicativas") é apenas transferir o problema para um nível mais abrangente, o das estruturas que dão conta, simultaneamente dessas orações e das coordenadas não-integradas, que claramente têm uma natureza paratática.

\subsection{Propriedades da oração encabeçada pelo conector que}

Ainda que as construções de que-conetivo partilhem com as coordenadas não-integradas a natureza paratática, elas põem problemas adicionais. Com efeito, as orações iniciadas por que-conetivo apresentam também propriedades características da subordinação. Nomeadamente, o conector que, como os complementadores conjuncionais, (i) só introduz frases finitas (43), diferentemente do que acontece com as conjunções coordenativas (44); (ii) só seleciona um constituinte frásico (45a), excluindo constituintes menores que TP mesmo que tenham conteúdo oracional, como as orações pequenas, (45b), em contraste com as conjunções de coordenação, (46); (iii) não legitima construções de gapping, como indica o estatuto de agramaticalidade dos exemplos em (47), que se comportam como a subordinada em (48a) e não como a coordenada em (48b):

(43) a. Dê-me esse dicionário, que eu quero/*querer guardar na estante.

b. Compre os ovos, que eu faço/*fazer o bolo.

c. Consulte o dicionário, que eu consulto/*consultar a gramática

(44) Eu quero [consultar o dicionário $e$ guardar na estante de seguida].

(45) a. Vamos dormir, que [тр eu estou com sono]

b. *Vamos dormir, que [or. Peq eu sonolenta]

(46) Ele achou [[Or. Peq a Maria cansada] $e$ [or. Peq a Ana febril]]

(47) a. *Não compre o gelado que nós _ um bolo

b. *Consulte o dicionário, que eu _ a gramática.

(48) a. *Ela comprou o gelado quando nós _ o bolo.

b. Tu compras o gelado e nós _ o bolo.

Estes dados indicam, pois, que, no domínio frásico sobre que tem escopo, que-conetivo não-argumental exibe propriedades de complementador conjuncional subordinativo.

\subsection{As orações de que-conetivo - hipotaxe, parataxe e parênteses}

Considerando as propriedades destacadas nas três secções anteriores, devemos admitir que as construções de que-conetivo não-argumental têm um caracter híbrido entre a coordenação não-integrada e a subordinação. Por

${ }^{8}$ Para mais argumentos a favor da distinção entre coordenação integrada e não-integrada/parentética, veja-se Matos, 2009. 
Estruturas paratáticas de que-conetivo em frases não-argumentais

outras palavras, a oração iniciada por que-conetivo estabelece uma relação de parataxe com a oração a que está associada, mas, no seu domínio local, que funciona como um conector subordinativo.

Este comportamento tem repercussões ao nível das estruturas sintáticas a atribuir a estas construções. Em sintaxe, em conformidade com a hipótese da estrutura sintagmática nua (Bare Phase Structure, Chomsky, 1995), assume-se que um sintagma não é intrinsecamente distinto do núcleo que o encabeça, e que a sua natureza categorial, ou etiqueta (ing. label), é a do núcleo que o projecta (Chomsky, 2013, 2015). Assim, se o núcleo for Comp, o sintagma correspondente será de natureza Complementador, mas, se o núcleo for Conj, a estrutura sintagmática obtida será de natureza Conjunção coordenativa.

Deste modo, assumindo que que-conetivo é o conector responsável pelo carácter simultaneamente paratático e hipotático das construções em que ocorre, teremos de admitir que ele instancia um núcleo funcional híbrido, uma nova categoria, chamemos-lhe Conj_Comp, que reúne em si as propriedades antagónicas da coordenação e da subordinação.

A ser criada, essa categoria capta única e especificamente as construções de que-conetivo não-argumental (e dos causais "explicativos"), uma vez que não caracteriza adequadamente a coordenação não-integrada, ilustrada em (41b) e em (49):

(49) O João não lhe telefonou, e ele era o seu melhor amigo.

Contudo, esta questão pode ser resolvida sem criarmos uma categoria funcional híbrida ou descurarmos a proximidade das construções de que-conetivo e a coordenação não-integrada, designada em Matos (2009) como parentética ${ }^{9}$, adoptando a proposta de Colaço \& Matos $(2016 \mathrm{a}, \mathrm{b})$ para as orações explicativas.

Como vimos em (43)-(48) as frases iniciadas por que-conetivo exibem características da subordinação. Contudo, relativamente à frase com que estão conectadas, as frases com que-conetivo apresentam um estatuto parentético, como indicam as seguintes propriedades: são frases não-integradas prosódica (50) e sintaticamente (51) na frase associada, e, embora usualmente surjam apensas a esta frase, como em (50) e (51), podem ocorrer interpoladas, $(52)^{10}$. Semanticamente, funcionam como comentários adicionais do locutor:

(50) a. Eu quero ir embora, que já é tarde!

b. Passe-me agora o dicionário de Português-Inglês, que eu guardo na estante.

c. Consulte a gramática, que eu consulto o dicionário.

(51) a. \#Não me dê o dicionário, que eu guardo na estante.

b. \#Só consulte a gramática, que eu consulto o dicionário.

c. Ele $e_{i}$ trabalha muitas horas por dia, que o João é um médico muito competente.

(52) a. Eu quero, que já é tarde, ir(-me) embora.

b. Passe-me agora, que eu guardo na estante, o dicionário de Português-Inglês.

c. Ele $\mathrm{i}_{\mathrm{i}}$ que o João é um médico muito competente, tem trabalhado muitas horas por dia.

\footnotetext{
${ }^{9}$ Ver para outras línguas, Kavalova (2007), entre outros.

${ }^{10} \mathrm{Um}$ dos revisores considerou como bem formadas as parentéticas apensas, mas não aceitou com facilidade as parentéticas interpoladas. Assim para este revisor as frases de que-conetivo são fundamentalmente parentéticas ancoradas, que se encontram fixas em posposição à oração hospedeira, e não parentéticas flutuantes, que podem ocorrer interpoladas em diferentes posições da frase hospedeira que modificam. Em trabalhos futuros estas alternativas deverão ser verificadas junto de um grupo mais representativo de falantes.
} 
Em conformidade com os dados apresentados, concluímos que estas construções envolvem mais de uma camada de estrutura sintática, cada uma delas projetada a partir de um núcleo funcional próprio: que-conetivo encabeça localmente o núcleo C(omp), conferindo a esta frase as características próprias da subordinação. Quanto à natureza parentética/paratática desta frase relativamente à frase que modifica, ela decorre da presença de um núcleo funcional, sem realização lexical, mas marcado prosodicamente pela pausa (e graficamente, pela vírgula, os parênteses ou os travessões), denominado $\square$ (Gartner, 2001), ou Par* (de Vries, 2012). Adotando, com Colaço \& Matos (2016b), a proposta de de Vries, a estrutura de um exemplo como (50a) poderia ser esquematicamente a explicitada em (53):

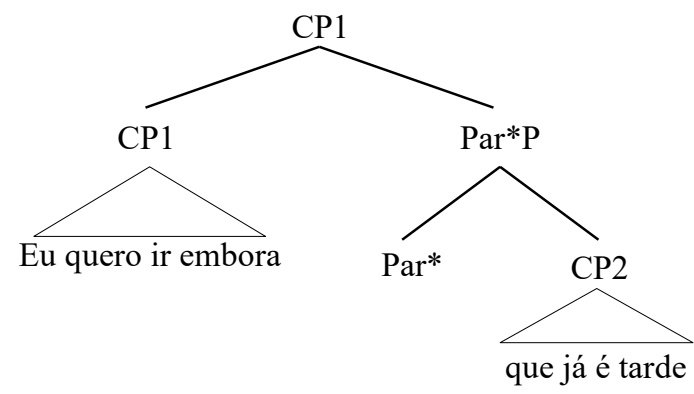

Como ilustrado em (53), Par* é um núcleo funcional que seleciona um único constituinte, no caso CP2, e projeta um sintagma Par*P, que se adjunge a CP1. Par*/Par*P têm como propriedades inerentes iniciar um novo domínio prosódico e bloquear c-comando a partir da expressão linguística hospedeira, em (53) CP1 Esta proposta permite tratar sintaticamente também os casos em que a parentética está encaixada. Assim, em (52c), a parentética surge como um modificador de TP, orientado para o locutor:

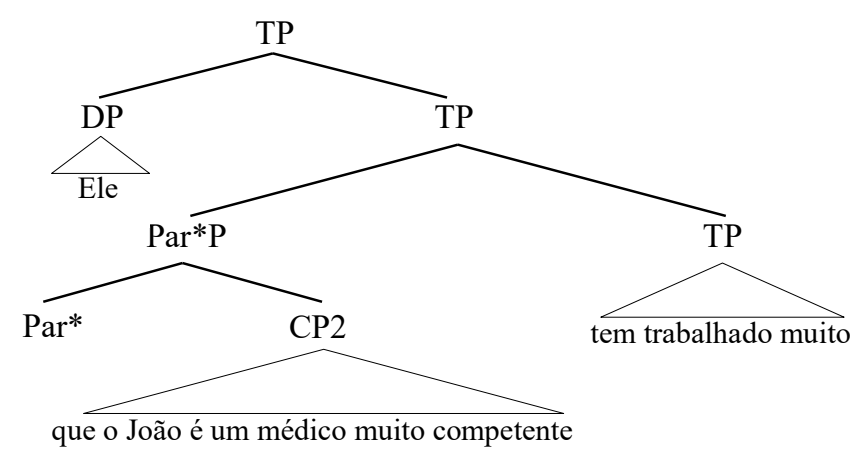


Estruturas paratáticas de que-conetivo em frases não-argumentais

Esta proposta de análise das expressões parentéticas apresenta vantagens sobre outras que tratam os parênteses como constituintes com autonomia sintática total relativamente à frase hospedeira, que só ao nível do discurso estabeleceriam um nexo de conexão com o hospedeiro. De entre estas propostas, destaca-se a denominada de orfandade radical dos parênteses, de Haegeman (1991/2009). Este tratamento de autonomia sintática radical e conexão ao discurso, aproxima os constituintes parentéticos dos casos de insubordinação do espanhol (55) e do catalão (56):

(55) Que viene (Gras; Sansineña, 2015: 507)

'(Ele/Ela) vem.'

(56) Que está tancada. [produzido quando o locutor constata que o interruptor da luz está estragado] (Corr 2016: 200)

No entanto, a aceitarmos esta proposta relativamente às parentéticas, esperaríamos que frases como as seguintes fossem possíveis em português, o que não acontece:

(57) *Que saiu.

(58) *Que está estragado/quebrado.

Do mesmo modo, os parênteses não têm subsistência própria na ausência de um hospedeiro, como mostra a anomalia pragmática dos seguintes enunciados na ausência da frase associada:

(59) a. \#Que já é tarde.

b. \#Que eu guardo na estante.

c. \#Que eu consulto o dicionário.

Assim, os dados discutidos neste trabalho revelam uma particularidade do português com relação a outras línguas românicas, como o espanhol ou o catalão, no sentido de que, em português, orações de que-conetivo nunca são insubordinadas.

\section{Conclusão}

Este artigo mostrou que as orações não-argumentais de que-conetivo em português, quando modificam um ato de fala, podem ter, além de uma interpretação explicativa, outras, nomeadamente de consequência/resultado. Defendemos que essa liberdade interpretativa resulta do facto de que este conector é semanticamente vazio e de que a interpretação das frases decorre do contexto linguístico e situacional. Que-conetivo distinguir-se-ia, dessa forma, de outros conectores como porque e pois, que teriam um valor causal/explicativo intrínseco. Contudo, apesar das diferenças interpretativas, vimos que as orações não-argumentais com que-conetivo apresentam comportamento sintático semelhante, e sugerimos que as suas propriedades parecem apontar para um estatuto híbrido entre a hipotaxe e a parataxe. A nossa proposta é que constituem CPs que exibem propriedades de subordinação no domínio local de C, mas que também são parentéticas, articulando-se parataticamente com a oração hospedeira, pela adjunção de Par*P, projeção do núcleo funcional Par*, sem realização lexical, mas marcado prosodicamente por uma pausa. 
Este estudo corrobora a hipótese, já amplamente discutida na literatura de que não há uma relação direta entre a natureza semântica das orações adverbiais e a sua estrutura sintática. Estudos futuros devem explorar a ocorrência dessas orações com uma variedade ampla de atos de fala, bem como investigar o papel de outros conectores, como pois e porque, que concorrem com que nesses contextos. Ademais, estudos comparativos sobre as orações de que-conetivo envolvendo outras línguas românicas podem contribuir para as discussões sobre o fenómeno da insubordinação.

\section{Referências:}

Alcina, J. \& J. Blecua (1975) Gramática Española. Barcelona: Ariel.

Chomsky, N. (1995) The Minimalist Program. Cambridge (MA): The MIT Press.

Chomsky, N. (2013) Problems of projection. Lingua, 130, pp. 33-49.

Chomsky, N. (2015) Problems of projections: Extensions. In. Elisa di Domenico, Cornelia Hamann e Simona Matteini (orgs.) Structures, strategies and beyond: Studies in honour of Adriana Belletti. Amsterdam: John Benjamins, pp. 1-16.

Colaço, M. \& G. Matos (2016a) A natureza paratática das causais explicativas em português. Revista da Associação Portuguesa de Linguística 1, pp. 182-208.

Colaço, M. \& G. Matos (2016b) Explicative clauses in Portuguese as a case of parentheses. In. E. Carrilho, A. Fiéis e S. Pereira (orgs) Romance Language and Linguistic Theory 10: Selected papers from 'Going Romance' 28. Amsterdam/Philadelphia: John Benjamins, pp. 43-60.

Corr, A. (2016) Ibero-Romance and the syntax of the utterance. Dissertação de doutoramento, Cambridge University.

Corver, N. (1997) The internal syntax of the Dutch extended adjectival projection. Natural Language and Linguistic Theory 15, pp. 89-368.

Cunha, C. \& L. Cintra (1984) Nova Gramática do Português Contemporâneo. Rio de Janeiro: Nova Fronteira.

Demonte, V. \& P. Masullo (1999) La predication: los complementos predicativos. In I. Bosque e V. Demonte (orgs.). Gramática Descriptiva de la Lengua Española. Vol. 2. Madrid: Espasa.

Demonte, V. \& O. Fernández-Soriano (2014) Evidentiality and illocutionary force: Spanish matrix que at the syntaxpragmatics interface. In Dufter, A. \& A. S. O. de Toledo y Huerta (orgs.). Left Sentence Peripheries in Spanish: Diachronic, Variationist and Comparative Perspectives. Amsterdam/Philadelphia: John Benjamins, pp. 217252.

Etxepare, R. (2014) Coordination and Subordination. In I. Hualde, O. Antxon e E. O'Rourke (orgs.) The Handbook of Hispanic Linguistics. Oxford: Wiley-Blackwell, pp. 503-532.

Evans, N. (2007) Insubordination and its uses. In I. Nikolaeva (org.). Finiteness: all over the clause. Oxford: Oxford University Press, pp. 366-431.

Giusti, Giuliana. (1991) Le frasi consecutive. In L. Renzi e G. Salvi (orgs.) Grande Grammatica Italiana di Consultazione, volume II. Bologna: Il Mulino, pp. 820-827.

Gras, P. \& M. S. Sansineña (2015) An interactional account of discourse-connective que-constructions in Spanish. Text \& Talk 35(4), pp. 505-529.

Haegeman, L. (1991) Parenthetical adverbials: The radical orphanage approach. In Shuki Chiba, Akira Ogawa, Yasuaki Fuiwara, Norio Yamada, Osamu Koma e Takao Yagi (orgs.) Aspects of Modern English: Papers Presented to Masatomo Ukaji on his 60th birthday. Tokyo: Kaitakushi, pp. 232-254. 
Estruturas paratáticas de que-conetivo em frases não-argumentais

Haegeman, L. (2012) Adverbial Clauses, Main Clause Phenomena, and the Composition of the Left Periphery.Oxford: Oxford University Press.

Heycock, C. (2006) Embedded root phenomena. In M. Everaert e H. van Riemsdijk (eds.) The Blackwell Companion to Syntax. Oxford: Blackwell, pp. 174-209.

Kavalova, Yordana (2007) And-parenthetical clauses. In Déhé \& Kavalova (eds). Parentheticals. Amsterdam/Philadelphia: John Benjamins, pp. 145-172.

Lobo, M. (2003) Aspectos da Sintaxe das orações subordinadas adverbiais do Português. Dissertação de doutoramento, Universidade Nova de Lisboa.

Lopes, A. C. M. (2012) Contributos para uma análise semântico-pragmática das causais de enunciação no português europeu contemporâneo. Alfa, 56(2), pp. 451-468.

Matos, G. (2004) Coordenação Frásica vs. Subordinação Adverbial. In T. Freitas e A. Mendes (orgs.). Actas do XIX Encontro Nacional da Associação Portuguesa de Linguística. Lisboa: APL, pp. 555-567.

Matos, G. (2006) Coordination de phrases vs. subordination adverbiale - propositions causales en portugais. In I. Brill e G. Rebuschi (orgs.). Faits de Langues: Revue de Linguistique 28 - Coordination et subordination: typologie et modélisation. Paris: Ophrys, pp. 169-180.

Matos, G. (2009) Appositive Sentences and the Structure(s) of Coordination. In. D. Torck, W. L. Wetzels (orgs.) Romance Language and Linguistic Theory 20006: Selected papers from 'Going Romance' 20. Amsterdam/Philadelphia: John Benjamins, pp. 159-173.

Potts, C. (2002) The Lexical Semantics of Parenthical-as and Appositive-which. Syntax 5(1), pp. 55-88.

Reis, M. (1997) Embedded Root Phenomena. In M. Everaert e H. van Riemsdijk (orgs.) The Blackwell Companion to Syntax. Malden, Oxford: Blackwell, pp. 174-209.

Rodrigues, P. (2018) Orações causais e estrutura informacional da sentença. Gragoatá 46, pp. 544-565.

Ross, J. R. (1967) Constraints on variables in syntax. Dissertação de doutoramento. Massachusetts Institute of Technology.

Said Ali, M. (1931) Gramática Histórica da língua Portuguesa. São Paulo: Edições Melhoramentos, 1964.

Sweetser, E. (1990) From etymology to pragmatics. Cambridge: Cambridge University Press.

de Vries, M. (2012) Unconventional Mergers. In Ways of Structure Building, Myriam Uribe-Etxebarria \& Vidal Valmala (eds), pp. 143-66. Oxford: Oxford University Press. 